\title{
COMPARATIVE EFFECTS OF THREE HERBS AND STANDARD HYPOGLYCAEMIC AGENTS ON BLOOD GLUCOSE IN NORMOGLYCAEMIC, HYPERGLYCAEMIC AND ALLOXAN-INDUCED DIABETIC MALE RATS
}

\author{
*OSINUBI AA', ENYE LA', ADESIYUN AE', AJAYI GO \\ Department of Anatomy, \\ Lagos State University College of Medicine, Ikeja, Nigeria. \\ Department of Clinical Pharmacy \& Biopharmacy, \\ Department of Pharmacognosy, Faculty of Pharmacy, \\ University of Lagos, Lagos, Nigeria. \\ *Corresponding author \\ E-mail:abrahamosinubi@yahoo.co.uk \\ Phone: 234-8023034954; 234-017949768
}

Parts of this work were read at the $19^{\mathrm{n}}$ World Diabetes Congress, Cape Town, South Africa (December, 2006).

\begin{abstract}
Background: The prevalence of diabetes mellitus has risen exponentially in the last decade and an increasing number of people are using herbal supplements.

Objective: We aimed to assess the relative efficacy of three promising herbs as potentially emerging alternative/adjunct treatment for diabetes.

Materials and Methods: One hundred and ninety-two male Sprague-Dawley rats were used. A third of the animals were randomly rendered diabetic with alloxan $(150 \mathrm{mg} / \mathrm{kg})$, another third injected $50 \%$ dextrose $(5 \mathrm{~g} / \mathrm{kg})$; and the last third constituted the controls. The rats were variously administered aqueous leaf extract of Momordica foetida $(500 \mathrm{mg} / \mathrm{kg})$, Vernonia amygdalina (500 mg/kg) and Tapinanthus butungii (500 mg/kg), glibenclamide (5 mg/kg) chlorpropamide (250 mg/kg), and human insulin lente (0.1 I.U./kg).

Results: Extract of Momordica foetida caused maximal anti-diabetic effect in six hours, Vernonia amygdalina ten hours, while Tapinanthus butungii continued to cause reduction after ten hours. The three extracts caused greater blood glucose reductions than glibenclamide in the diabetic rats, while exhibiting comparable effects with chlorpropamide and insulin.

Conclusions: Tapinanthus butungii is more effective in lowering blood glucose than Momordica foetida and Vernonia amygdalina in alloxan-induced diabetic rats. Leaf extract of Momordica foetida should be useful in rapidly lowering blood glucose, while that of Tapinanthus butungii in situations that require more subtle reductions and in conditions in which prolonged hypoglycaemic actions are desirable.
\end{abstract}

Keywords: Mormordica foetida, Vernonia amygdalina, Tapinanthus butungii, Leaf, Alloxan-induced diabetes mellitus.

\section{INTRODUCTION}

Diabetes mellitus has been recognized as a clinical syndrome since ancient times, and remains a crippling global health problem today. It is due to absolute or relative deficiency or diminished effectiveness of circulating insulin. It is widespread and is one of the most common chronic diseases. Current estimates suggest that approximately 246 million people worldwide suffer from diabetes mellitus (1). Despite major inroads into understanding the pathophysiology and treatment of this insidious disease, it had continued to be a major health problem worldwide. The possibility of its management by the oral administration of hypoglycaemic agents had stimulated great interest in recent years. Current therapies seem to be insufficient to prevent diabetic complications, with a two- to four-fold likelihood for developing cardiovascular events (2). Despite the large armamentarium presently available, the progressive deterioration of diabetes control is such that treatment is still insufficient, with the majority of type 2 diabetes patients eventually requiring insulin therapy to achieve targeted glycaemic levels (3), and an estimated $75 \%$ dying of diabetes-related complications from cardiovascular disease (4). As a result of these limitations, there is a continuous need for the development of novel health promotion strategies and therapeutic modalities. While physicians advocate aggressive use of drugs to tighten glucose control and attenuate cardiovascular disease risk factors, many patients are more inclined toward use of alternative or complementary therapies that include diet, food supplements and herbal medicine. The use of herbs has more than tripled over the last 10 years (5). Little scientific evidence exists to support the numerous herbs used to improve diabetes and diabetes-related metabolic disorders (6). For a long time diabetes patients have been treated orally with several medicinal plants or their extracts based on folk medicine (7). Based on the World Health Organization recommendations on diabetes mellitus (8), investigations of hypoglycaemic agents of plant origin used in traditional medicine are important. The use of herbal products for medicinal benefits has playedan important role in nearly every culture on earth and for many years, the search for anti-diabetic products will continue to focus on plants and other natural resources. Investigators have consistently found that several plant products showed unique hypoglycaemic activities in diabetic animal models. Animal models of diabetes mellitus are of two main groups: (a) a genetic insulin-resistant diabetic model such as yellow kk mice, db/db mice and Zucker fatty rat; and (b) an experimental diabetic model such as streptozotocin- or alloxaninduced insulin deficiency diabetic model. An alloxan-induced selective decrease in b-cell mass leads to deficient insulin secretion by attenuating insulin pulse mass, and associated 
decreased hepatic insulin clearance and relative hyperglucagonaemia thereby simulating the pattern of islet dysfunction observed in type 2 diabetes mellitus (9).

This present study sought to compare the relative efficacy of three plants with type 2 diabetes therapeutic potential, found in South-western Nigeria, using alloxan-induced insulin deficiency diabetic model. Momordica foetida (of the family Cucurbitaceae) is a common inhabitant of forest edges, woodland, wooded grassland and riverine fringes. It is a perennial herb with prostrate or climbing stems. The plant emits an unpleasant smell when crushed. The bright orange, softly spiny fruit splits open into three valves, revealing seeds embedded in bright red jelly. Methanolic extract of whole part of Momordica foetida has been shown to contain a hypoglycaemic principle (foetidin) identical with charantin found in Momordica charantia $(10,11)$, an established hypoglycaemic plant. Vernonia amygdalina (of the family Compositae) has been reported to have anti-hyperglycaemic effect $(14,15)$. Major constituents of the extract from the leaves of Vernonia amygdalina include sesquiterpene lactones (vernodalin, vernolide, hydroxyvernolide), and steroid glucosides (vernonioside A1-A4: the bitter-tasting constituents and vernonioside B1-B3) (12,13). It has been reported that a sesquiterpene lactone isolated from the extract of Ambrosia maritima is an effective hypoglycemic agent (16). Tapinanthus butungii (of the family Loranthaceae commonly referred to as mistletoe) parasitizes on Albizia glaberrima. A wide range of biological activity, including causing hypoglycaemia, has been ascribed to this group of plants (17) The aim of this study was to assess the relative effects of aqueous leaf extract of Momordica foetida, Vernonia amygdalina and Tapinanthus butungii at lowering blood glucose levels in normoglycaemic, hyperglycaemic and alloxan-induced diabetic male SpragueDawley rats, with a view to provide basic data concerning their relative potential as adjunct or main therapy of type 2 diabetes mellitus.

\section{MATERIALS AND METHODS}

\section{Plant material}

Fresh green leaves of Momordica foetida, Vernonia amygdalina and Tapinanthus butungii were harvested from the garden of the Anatomy Department of the College of Medicine and Botanical Garden, University of Lagos in the month of September, 2005. The leaves of Momordica foetida and Vernonia amygdalina were identified and authenticated by taxonomists in the Department of Botany of the University of Lagos, Lagos, Nigeria. The Department keeps voucher specimens of the plants in its herbaria. Identification and authentication of the leaves of Tapinanthus butungii were carried out at the Forestry Research Institute of Nigeria, Ibadan, Nigeria, where voucher specimen was deposited. The extraction process was carried out in the Department of Pharmacognosy, Faculty of Pharmacy, University of Lagos, Lagos, Nigeria. Briefly, the completely air-dried leaves of Momordica foetida (500 g), Vernonia amygdalina (500 g) and Tapinanthus butungii (500 g) were reduced to powdery form, which was placed in distilled water and allowed to boil, simmering for one hour. The water extract was dialyzed and the internal solution lyophilized. The powder obtained (Momordica foetida $[3.00 \mathrm{~g}, 0.60 \%$ yield]; Vernonia amygdalina $[5.05 \mathrm{~g}$, $1.10 \%$ yield] and Tapinanthus butungii [9.50 g, $1.90 \%$ yield]) was stored at $4{ }^{\circ} \mathrm{C}$ before use and was prepared in distilled water for pharmacological studies. The treated animals had each of the extract at the dose of $500 \mathrm{mg} / \mathrm{kg}$ body weight.

\section{Animal material}

One hundred and ninety-two adult male Sprague-Dawley rats weighing 180-220 g were used for the experiments. They were procured from the Animal House of the College of Medicine, University of Lagos. They were allowed to acclimatize and maintained under standard photoperiodic condition in the Rat Room of the Department of Anatomy for two weeks. They were allowed unrestricted access to rat chow (Pfizer Mill, Lagos, Nigeria) and pipe-borne water in the Anatomy Department. The rats were weighed, and randomly divided into three main groups (G1-3) of 64 rats each. The animals in the 3 main groups were subdivided into 8 subgroups (G1a, G1b, G1c, G1d, G1e, G1f, G1g, G1h, G2a...G3h), of 8 rats each. G1 were normoglycaemic, G2, hyperglycaemic and G3, diabetic rats. Subgroups a-g were (a) control rats treated with intraperitoneal injections of distilled water; (b) control rats treated with distilled water via gastric intubation; (c) rats treated orally by gavage with $500 \mathrm{mg} / \mathrm{kg}$ body weight of aqueous leaf extract of Momordica foetida; (d) rats treated orally by gavage with $500 \mathrm{mg} / \mathrm{kg}$ body weight of aqueous leaf extract of Vernonia amygdalina; (e) rats treated orally by gavage with $500 \mathrm{mg} / \mathrm{kg}$ body weight of aqueous leaf extract of Tapinanthus; (f) rats administered $10 \mathrm{mg} / \mathrm{kg}$ of glibenclamide orally by gavage; (g) rats given $250 \mathrm{mg} / \mathrm{kg}$ of chlorpropamide orally by gavage; and (h) those given 0.1 I.U./kg body weight of human insulin lente subcutaneously. All animals were observed for clinical signs of drug toxicity (such as tremors, weakness, refusal of feeds, weight loss, hair-loss, coma and death) throughout the duration of the experiment and four weeks thereafter. All procedures involving animals in this study conformed to the guiding principles for research involving animals as recommended by the Declaration of Helsinki and the Guiding Principles in the Care and Use of Animals (18) and were approved by the Departmental Committee on the Use and Care of Animals.

\section{Induction of experimental diabetes}

Diabetes was induced (in the group of diabetic rats) with alloxan. Crystalline powdered alloxan (2.5 g) (NAFCO Nigeria Limited) was taken and dissolved in $62.5 \mathrm{ml}$ of distilled water to yield a concentration of $40 \mathrm{mg} / \mathrm{ml}$. One hundred and fifty milligrams per kilogram body weight of alloxan was administered intraperitoneally (19) to 64 of the animals, after an overnight fast (access to only water) of 12 hours to make them more susceptible to developing diabetes $(20,21)$. Only rats with serum glucose levels greater than $400 \mathrm{mg} / \mathrm{dl}$ were used in experiments.

\section{Induction of hyperglycaemic state}

Rats were injected $5 \mathrm{~g} / \mathrm{kg}$ of $50 \%$ dextrose in water subcutaneously. The hyperglycaemic state was assessed in dextrose-treated rats by measuring non-fasting blood concentration of glucose 30 minutes post-dextrose injection. Only rats with serum glucose levels greater than $110 \mathrm{mg} / \mathrm{dl}$ were used in experiments.

\section{Experimental procedure}

Touch Basic made by Lifescan (Johnson \& Johnson Company, California, USA) and the results were read off on the meter 45 seconds after application of samples to the strips. The technical performance of the glucometer used was evaluated by comparison with standard laboratory method of blood glucose estimation (spectrophotometer) at the beginning, midway and at end of the experiment as previously described by Ajala et al., (22). In order to minimize the effects of circadian rhythm on our results, the experiment was structured in such a way that the serial blood glucose estimation of half of the rats were commenced at $0800 \mathrm{~h}(8$ a.m.) and subsequently at $0900 \mathrm{~h}$ (9 a.m.), 1100h (11 a.m.), 1300h (1 p.m.), 1500h (3 p.m.), 1700h (5 p.m.) and 1900h (7 p.m.), while those of the other half were commenced at $2000 \mathrm{~h}$ (8 p.m.) and subsequently at $2100 \mathrm{~h}$ (9 p.m.), 2300h (11 p.m.), 0100h (1 a.m.), 
0300h ( 3 a.m.), 0500h (5 a.m.) and 0700h (7 a.m.). The serial blood glucose levels taken were the means of these two divisions. We have previously described a circadian rhythm for blood glucose concentration in male Sprague-Dawley rats in Lagos, with peak at $1900 \mathrm{~h}$ and nadir at $1100 \mathrm{~h}(23)$.

\section{Data Analysis}

Statistical analysis was performed using Microsoft excel. Results were expressed as means \pm standard deviation (SD) and subjected to statistical analysis using one-way analysis of variance (ANOVA) and the Scheffe's post-hoc test. The significance level considered was $p<0.05$.

\section{RESULTS}

\section{Activity in normoglycaemic rats}

Significant $(p<0.05-0.01)$ hypoglycaemic effects of the extract of Momordica foetida, Vernonia amygdalina and Tapinanthus butungii were observed within 4, 10 and 8 hours after oral administration (table 1), respectively. The percentage of maximum reduction in blood glucose concentrations caused by the aqueous leaf extract of Momordica foetida, Vernonia amygdalina and Tapinanthus butungii were 22.05, 25.76 and $17.44 \%$, respectively and these values are statistically $(p<0.001)$ different from those of the controls.

\section{Activity in hyperglycaemic rats}

Significant $(p<0.05)$ anti-hyperglycaemic effects of the extract of Momordica foetida, Vernonia amygdalina and
Tapinanthus butungii were observed within 4, 6 and 8 hours after oral administration (table 2), respectively. The percentage of maximum reductions in blood glucose concentrations caused by the aqueous leaf extract of Momordica foetida, Vernonia amygdalina and Tapinanthus butungii in rats pretreated with 50\% dextrose were 53.87, 53.61 and $49.50 \%$ respectively. These reductions caused by the three herbs were comparable $(p<0.05)$ with those caused by glibenclamide and chlorpropamide (table 2).

\section{Activity in alloxan-induced diabetic rats}

In the diabetic rats, the aqueous leaf extract of Momordica foetida caused a maximum reduction in blood glucose level six hours after administration, while that of Vernonia amygdalina was ten hours after. The aqueous leaf extract of Tapinanthus butungii on the other hand continued to cause reduction after 10 hours of administration. Of great significance was that the three extracts caused greater blood glucose reductions than glibenclamide and chlopropamide in the alloxan-induced diabetic rats, while they exhibited significant anti-diabetic effects comparable with that insulin lente (table 3).

Our results also showed that there were no significant differences in blood glucose levels of rats that had distilled water intraperitoneally and those that were similarly treated by gastric intubation (tables 1-3).

There were no obvious signs of toxicity (such as tremors, weakness, refusal of feeds, weight loss, hair-loss, coma and death) observed in any of the animals throughout the duration of our observation.

Table 1: Effects of aqueous leaf extract of Momordica foetida (500 $\mathrm{mg} / \mathrm{kg}$, per oral), Vernonia amygdalina (500 $\mathrm{mg} / \mathrm{kg}, \mathrm{per} \mathrm{oral})$, Tapinanthus butungii (500 mg/kg, per oral), glibenclamide $(10 \mathrm{mg} / \mathrm{kg}$, per oral), chlorpropamide $(250 \mathrm{mg} / \mathrm{kg}$, per oral) and human insulin lente (0.1 I.U./kg, subcutaneously) on blood glucose on blood glucose concentrations of normoglycaemic rats (mg/dl)

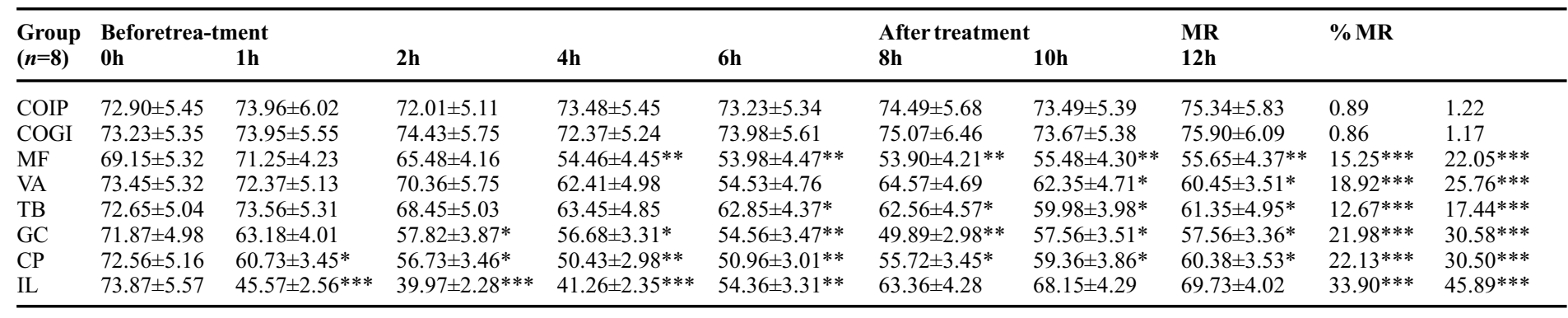

Table 2: Effects of aqueous leaf extract of Momordica foetida $(500 \mathrm{mg} / \mathrm{kg}$, per oral $)$, Vernonia amygdalina $(500 \mathrm{mg} / \mathrm{kg}$, per oral $)$, Tapinanthus butungii $(500 \mathrm{mg} / \mathrm{kg}$, per oral $)$, glibenclamide $(10 \mathrm{mg} / \mathrm{kg}$, per oral $)$, chlorpropamide $(250 \mathrm{mg} / \mathrm{kg}$, per oral $)$ and human insulin lente (0.1 I.U./kg, subcutaneously) on blood glucose on blood glucose concentrations of hyperglycaemic rats (mg/dl)

\begin{tabular}{|c|c|c|c|c|c|c|c|c|c|c|}
\hline \multirow{2}{*}{$\begin{array}{l}\text { Group } \\
(n=8)\end{array}$} & \multicolumn{5}{|c|}{ Before treatment } & \multicolumn{2}{|c|}{ After treatment } & \multirow{2}{*}{$\begin{array}{l}\text { MR } \\
12 \mathrm{~h}\end{array}$} & \multicolumn{2}{|l|}{$\%$ MR } \\
\hline & Oh & $1 \mathrm{~h}$ & $2 \mathbf{h}$ & $4 h$ & $6 h$ & $\mathbf{8 h}$ & $10 \mathrm{~h}$ & & & \\
\hline COIP & $117.45 \pm 10.01$ & $80.32 \pm 7.38$ & $75.48 \pm 6.03$ & $74.57 \pm 5.76$ & $73.48 \pm 4.65$ & $73.91 \pm 4.45$ & $74.00 \pm 5.05$ & $72.96 \pm 5.15$ & 44.49 & 37.88 \\
\hline COGI & $116.28 \pm 9.98$ & $79.98 \pm 6.98$ & $74.65 \pm 6.21$ & $74.23 \pm 5.02$ & $73.45 \pm 5.43$ & $73.51 \pm 5.15$ & $73.79 \pm 5.17$ & $71.94 \pm 5.11$ & 44.34 & 38.13 \\
\hline $\mathrm{MF}$ & $118.17 \pm 9.51$ & $71.03 \pm 6.92$ & $65.45 \pm 4.99$ & $56.17 \pm 4.47^{*}$ & $55.90 \pm 4.67 *$ & $54.56 \pm 4.45^{*}$ & $54.51 \pm 4.54 *$ & $56.24 \pm 4.56^{*}$ & $63.66^{*}$ & $53.87 *$ \\
\hline VA & $117.86 \pm 9.45$ & $72.49 \pm 6.42$ & $71.48 \pm 5.45$ & $67.57 \pm 5.06$ & $61.32 \pm 4.56^{*}$ & $58.43 \pm 4.55^{*}$ & $57.35 \pm 4.65^{*}$ & $54.67 \pm 3.87^{*}$ & $63.19 *$ & $53.61 *$ \\
\hline TB & $119.27 \pm 10.01$ & $76.42 \pm 6.75$ & $72.46 \pm 5.34$ & $68.32 \pm 5.01$ & $65.38 \pm 4.76$ & $63.36 \pm 4.65 *$ & $61.01 \pm 3.56^{*}$ & $60.23 \pm 4.71^{*}$ & $59.04 *$ & $49.50 *$ \\
\hline $\mathrm{GC}$ & $117.23 \pm 9.48$ & $68.69 \pm 5.43$ & $58.77 \pm 4.82 *$ & $56.11 \pm 3.83^{*}$ & $52.43 \pm 3.77 *$ & $50.56 \pm 3.53 * *$ & $58.05 \pm 4.78^{*}$ & $56.64 \pm 4.21 *$ & $66.67 *$ & $56.87^{*}$ \\
\hline $\mathrm{CP}$ & $115.57 \pm 9.13$ & $65.43 \pm 5.21$ & $55.46 \pm 3.86^{*}$ & $51.25 \pm 3.45 * *$ & $51.38 \pm 3.54 * *$ & $55.43 \pm 3.85^{*}$ & $58.55 \pm 3.76^{*}$ & $62.34 \pm 4.76$ & $64.32 *$ & $55.66^{*}$ \\
\hline IL & $118.35 \pm 9.46$ & $55.01 \pm 3.42 * *$ & $44.57 \pm 3.21 * * *$ & $44.10 \pm 3.28 * * *$ & $55.66 \pm 3.76^{* *}$ & $61.54 \pm 4.05^{*}$ & $67.89 \pm 5.12$ & $68.99 \pm 5.21$ & $74.25 * *$ & $62.74 * *$ \\
\hline
\end{tabular}


Table 3: Effects of aqueous leaf extract of Momordica foetida $(500 \mathrm{mg} / \mathrm{kg}$, per oral $)$, Vernonia amygdalina $(500 \mathrm{mg} / \mathrm{kg}$, per oral), Tapinanthus butungii $(500 \mathrm{mg} / \mathrm{kg}$, per oral $)$, glibenclamide $(10 \mathrm{mg} / \mathrm{kg}$, per oral $)$, chlorpropamide $(250 \mathrm{mg} / \mathrm{kg}$, per oral $)$ and human insulin lente $(0.1 \mathrm{I} . \mathrm{U} . / \mathrm{kg}$, subcutaneously) on blood glucose on blood glucose concentrations of diabetic rats (mg/dl)

\begin{tabular}{|c|c|c|c|c|c|c|c|c|c|c|}
\hline $\begin{array}{l}\text { Group } \\
(n=8)\end{array}$ & $\begin{array}{l}\text { Before treatme } \\
\text { 0h }\end{array}$ & $\begin{array}{l}n t \\
1 h\end{array}$ & $2 \mathrm{~h}$ & $4 h$ & $6 h$ & $\begin{array}{l}\text { After treatment } \\
\mathbf{8 h}\end{array}$ & $10 \mathrm{~h}$ & $12 \mathrm{~h}$ & MR & $\% \mathrm{MR}$ \\
\hline COIP & $501.23 \pm 14.01$ & $501.07 \pm 14.54$ & $545.49 \pm 15.68$ & $555.24 \pm 15.32$ & $545.28 \pm 15.44$ & $564.68 \pm 15.81$ & $566.58 \pm 15.86$ & $578.42 \pm 15.98$ & 0.16 & 0.03 \\
\hline $\mathrm{COG}$ & $519.34 \pm 14.01$ & $522.39 \pm 14.11$ & $518.99 \pm 14.27$ & $524.75 \pm 15.48$ & $537.18 \pm 15.34$ & $554.02 \pm 15.56$ & $555.49 \pm 15.65$ & $566.17 \pm 15.89$ & 0.35 & 0.07 \\
\hline MF & $483.50 \pm 16.11$ & $478.70 \pm 15.21$ & $387.73 \pm 14.20^{*}$ & $324.33 \pm 14.4 * *$ & $155.70 \pm 9.51 * * *$ & $262.8 \pm 10.90 * *$ & $275.54 \pm 11.33^{* *}$ & $298.40 \pm 12.11 * *$ & $338.8^{* * *}$ & $70.07 * * *$ \\
\hline VA & $502.77 \pm 15.98$ & $487.98 \pm 14.23$ & $466.87 \pm 14.76^{*}$ & $383.23 \pm 13.04 * *$ & $324.63 \pm 10.34 * *$ & $210.13 \pm 9.90 * * *$ & $191.78 \pm 9.23 * * *$ & $192.49 \pm 9.56 * * *$ & $310.99 * * *$ & $61.86^{* * *}$ \\
\hline TB & $530.49 \pm 15.34$ & $473.11 \pm 14.59$ & $375.45 \pm 14.32 *$ & $255.34 \pm 10.21 * *$ & $212.89 \pm 10.21 * *$ & $172.38 \pm 10.34 * * *$ & $162.10 \pm 9.01 * * *$ & $145.20 \pm 8.56 * * *$ & $385.29 * * *$ & $72.63 * * *$ \\
\hline GC & $519.35 \pm 15.35$ & $469.87 \pm 14.42$ & $523.23 \pm 15.64$ & $517.53 \pm 15.38$ & $495.57 \pm 15.24$ & $485.64 \pm 14.49$ & $463.01 \pm 14.01$ & $465.19 \pm 14.25$ & 60.22 & 11.51 \\
\hline $\mathrm{CP}$ & $482.34 \pm 14.27$ & $516.56 \pm 15.01$ & $499.67 \pm 15.11$ & $474.21 \pm 15.02$ & $421.31 \pm 14.45$ & $467.90 \pm 14.73$ & $499.92 \pm 12.21$ & $455.62 \pm 14.68$ & 95.25 & 18.44 \\
\hline IL & $526.57 \pm 15.18$ & $165.86 \pm 8.50 * * *$ & $155.45 \pm 7.56 * * *$ & $317.37 \pm 12.65^{*}$ & $343.28 \pm 13.84^{*}$ & $466.39 \pm 14.49$ & $498.59 \pm 15.12$ & $501.46 \pm 15.21$ & $371.12 * * *$ & $70.48 * * *$ \\
\hline
\end{tabular}

\section{Legend for tables 1-3}

Values given represent the means $\pm \mathrm{SD}$ (standard deviation) of 8 observations

$*: p<0.05 ; * *: p<0.01 ; * * *: p<0.001$

MR: Maximum reduction of blood glucose concentration

COIP: Control group of rats that had $2 \mathrm{ml} / \mathrm{kg}$ of distilled water intraperitoneally

COGI: Control group of rats that had $2 \mathrm{ml} / \mathrm{kg}$ of distilled water via gastric intubation

\section{DISCUSSION}

Though, insulin is presently one of the most important therapeutic agents known to medicine, efforts have continued to seek for insulin substitutes from plant sources for the treatment of diabetes mellitus (24). It is clear from the results of this experimental animal study that the tested aqueous leaf extracts of Momordica foetida, Vernonia amygdalina and Tapinanthus butungii induced significant reductions $(p<0.05-0.001)$ in blood glucose concentrations of normoglycaemic, hyperglycaemic and alloxan-induced diabetic rats. The findings of this investigation may suggest that the plant extracts could, at least in part, stimulate insulin production and glucose utilization, like glibenclamide and chlorpropamide, to bring about their blood glucose reductions in this mammalian experimental model used. It was observed that aqueous leaf extract of Momordica foetida has faster onset of hypoglycaemic and anti-hyperglycaemic actions than those of Vernonia amygdalina and Tapinanthus butungii, while Tapinanthus butungii has a longer anti-diabetic action than Momordica foetida and Vernonia amygdalina. It was also noted that the leaf extracts of Momordica foetida and Vernonia amygdalina were more effective in lowering blood glucose levels than Tapinanthus butungii in normoglycaemic and hyperglycaemic rats, while that of Tapinanthus butungii was more effective than the other two in the diabetic rats. The three herbs investigated had more anti-diabetic effects than glibenclamide and chlorpropamide, while having comparable effects with insulin lente. The fact that these extracts caused significant reductions in blood glucose levels in alloxan-induced diabetic rats suggests that these plants may act in yet undetermined ways aside stimulating insulin production from the pancreatic islets since the latter would have been severely damaged by alloxan. However, stimulation of the undamaged or residual pancreatic islets to produce insulin cannot be ruled out since both glibenclamide and chlorpropamide caused slight but insignificant reductions in blood glucose levels in alloxan-induced diabetic rats. Although these present findings are suggestive of relative differences in the hypoglycaemic, anti-hyperglycaemic and anti-diabetic efficacies in the fresh leaves of Momordica foetida, Vernonia amygdalina and Tapinanthus butungii (at single doses), the reasons and precise mechanism for these differences require further studies for
MF: Group of rats that had aqueous leaf extract of Momordica foetida

VA: Group of rats that were treated with aqueous leaf extract of Vernonia amygdalina

TB: Group of rats that were treated with aqueous leaf extract of Tapinanthus butungii

GC: Group of rats that were administered glibenclamide

CP: Group of rats that were treated with chlorpropamide

TB: Group of rats that were administered human insulin lente

appropriate elucidation. Further studies will also incorporate varying doses of the three herbs, comparison of their $\mathrm{ED}_{\mathrm{s}^{\circ}}$ doses, measurements of serum insulin levels and evaluation of lipid profiles in the animals.

\section{CONCLUSIONS}

The results of this experimental animal study suggest that aqueous leaf extract of Momordica foetida has faster onset of actions (hypoglycaemic and anti-hyperglycaemic) than those of Vernonia amygdalina and Tapinanthus butungii at the doses used. Our results suggest that aqueous leaf extract of Tapinanthus butungii has a longer anti-diabetic action than Momordica foetida and Vernonia amygdalina at the doses compared. This animal study also suggest that at these single dosages of the extracts, aqueous leaf extracts of Momordica foetida and Vernonia amygdalina are more effective in lowering blood glucose than Tapinanthus butungii in normoglycaemic and hyperglycaemic rats, while that of Tapinanthus butungii is more effective than the other two in diabetic rats.

\section{REFERENCES}

1. Antonio Ceriello and Stephen Colagiuri. Guideline for the management of post-meal blood glucose. Diabetes Voice (International Diabetes Federation), 2007; 52(3): 9-11.

2. Haffner SM, Lehto S, Ronnemaa T, Pyorala K, Laakso M. Mortality from coronary heart disease in subjects with type 2 diabetes and in nondiabetic subjects with and without prior myocardial infarction. NEngl JMed, 1998; 339: 229-234.

3. Turner RC, Cull CA, Frighi V, Holman RR. Glycemic control with diet, sulfonylurea, metformin, or insulin in patients with type 2 diabetes mellitus: progressive requirement for multiple therapies (UKPDS 49), UK Prospective Diabetes Study (UKPDS) group. JAMA, 2000; 281:2005-2012.

4. Vuksan V, Sievenpiper JL, Xu Z, Wong EYY, Jenkins AL, Beljan-Zdravkovic U, et al., Konjac-Mannan and American Ginsing: Emerging Alternative Therapies for Type 2 Diabetes Mellitus. JAm Coll Nutr, 2001; 20: 370S-380S.

5. Eisenberg DM, Davis RB, Ettner SL, Appel S, Wilkey S, Van Rompay M, et al., Trends in alternative medicine use in the 
United States, 1990-1997: Result of follow-up national survey. JAMA, 1998; 280: 1569-1575.

6. Lo HC, Tu ST, Lin KC, Lin SC. The anti-hyperglycemic activity of the fruiting body of Cordyceps in diabetic rats induced by nicotinamide and streptozotocin. Life Sci, 2004; 74: 2897-2908.

7. Akhtar FM, Ali MR. Study of the antidiabetic effect of a compound medicinal plant prescription in normal and diabetic rabbit. J Pakistan Med Assoc, 1984; 34: 239-244.

8. World Health Organization. The WHO Committee on Diabetes Mellitus: Second Report. Technical Report Series 646. Geneva: World Health Organization, 1980, pp. 61.

9. Aleeva GN, Kiyasov AP, Minnebaev MM, Burykin IM, Khafiz'yanova RK. Changes in the count of pancreatic betaand alpha-cells and blood glucose level in rats with alloxaninduced diabetes. Bull Exp Biol Med, 2002; 133: 127-129.

10. Olaniyi AA. A neutral constituent of Momordica foetida. Lloydia, 1975; 38:361-362.

11. Marquis VO, Adanlawo TA, Olaniyi AA. The effect of foetidin from Momordica foetida on blood glucose level of albino rats. Planta Med, 1977; 31:367-374.

12. Koshimizu K, Ohigashi H, Huffman MA. Use of Vernonia amygdalina by wild chimpanzee: possible roles of its bitter and related constituents. Physiol Behav, 1994; 56: 12091216.

13. Babalola OO, Anetor JI, Adeniyi FA. Amelioration of carbon tetrachloride-induced hepatotoxicity by terpenoid extract from leaves of Vernonia amydgalina. Afr J Med Med Sci, 2001; 30: 91-93.

14. Adejuwon SA, Osinubi AA, Noronha CC, Okanlawon AO. Acute effects of Vernonia amygdalina on blood glucose levels in normoglycaemic and alloxan-induced diabetic male Sprague-Dawley rats. West Afr J Anat, 2005; 8: 161-168.
15. Osinubi AA. Effects of Vernonia amygdalina and chlorpropamide on Blood Glucose. Medical Journal of Islamic World Academy of Sciences, 2007; 16(3): 115-119.

16. Kiliani AI, Ibraheem FK, Kamel NAH, Hareedi MA, Ali AA, Shahwan MM. 1990. Proceedings of $8^{\text {Annual Scientific }}$ Conference of Islamic Academy of Sciences, Cairo Egypt.

17. Osinubi AA, Ajayi OG, Adesiyun AE. Evaluation of the antidiabetic effect of aqueous leaf extract of Tapinanthus butungii in male Sprague-Dawley rats. Medical Journal of Islamic World Academy of Sciences, 2006; 16(1): 41-47.

18. American Physiological Society. Guiding principles for research involving animals and human beings. Am J Physiol Regul Integr Comp Physiol, 2002; 283: R281-R283.

19. Szkudelski T. The Mechanism of Alloxan and Streptozotocin Action in B Cells of the Rat Pancreas Physiol Res, 2001; 50: 536-546.

20. Katsumata K, Katsumata K Jr, Katsumata Y. Protective effect of diltiazem hydrochloride on the occurrence of alloxan- or streptozotocin-induced diabetes in rats. Horm Metab Res, 1992; 24: 508-510.

21. Szkudelski T, Kandulska K, Okulicz M. Alloxan in vivo does not only exert deleterious effects on pancreatic B cells. Physiol Res, 1998; 47: 343-346.

22. Ajala MO, Oladipo OO, Fasanmade O, Adewole TA. Laboratory assessment of three glucometers. Afr J Med Sci, 2003; 32: 279-282.

23. Osinubi AA, Udeh RA, Akpantah AO, Noronha CC, Okanlawon OA. The Circadian Rhythm of Blood Glucose in adult male Sprague-Dawley rats in Lagos. J Clin Sci, 2003; 3: $1-4$.

24. Erenmemisoglu A, Kelestimur F, Koker AH, Ustun H, Tekol Y, Ustdal M. Hypoglycaemic effect of Zizyphus jujuba leaves. JPharm Pharmacol, 1995; 47: 72-74. 